\title{
SARS-CoV-2 causes senescence in human cells and exacerbates the senescence-associated secretory phenotype through TLR-3
}

Utkarsh Tripathi ${ }^{1}$, Rayhane Nchioua ${ }^{2}$, Larissa G. P. Langhi Prata ${ }^{1}$, Yi Zhu ${ }^{1,3}$, Erin O. Wissler Gerdes ${ }^{1}$, Nino Giorgadze1, Tamar Pirtskhalava1 ${ }^{1}$, Erik Parker ${ }^{6}$, Ailing Xue ${ }^{1}$, Jair Machado Espindola-Netto ${ }^{1}$, Steffen Stenger ${ }^{4}$, Paul D. Robbins ${ }^{5}$, Laura J. Niedernhofer ${ }^{5}$, Stephanie L. Dickinson ${ }^{6}$, David B. Allison ${ }^{6}$, Frank Kirchhoff², Konstantin Maria Johannes Sparrer², Tamar Tchkonia ${ }^{1,3}$, James L. Kirkland ${ }^{1,3,7}$

\author{
${ }^{1}$ Robert and Arlene Kogod Center on Aging, Mayo Clinic, Rochester, MN 55905, USA \\ ${ }^{2}$ Institute of Molecular Virology, Ulm University Medical Center, Ulm 89081, Germany \\ ${ }^{3}$ Department of Physiology and Bioengineering, Mayo Clinic, Rochester, MN 55905, USA \\ ${ }^{4}$ Institute for Medical Microbiology and Hygiene, Ulm University Medical Center, Ulm 89081, Germany \\ ${ }^{5}$ Institute on the Biology of Aging and Metabolism, Department of Biochemistry, Molecular Biology and \\ Biophysics, University of Minnesota, Minneapolis, MN 55455, USA \\ ${ }^{6}$ Department of Epidemiology and Biostatistics, School of Public Health, Indiana University-Bloomington, \\ Bloomington, IN 47405, USA \\ ${ }^{7}$ Division of General Internal Medicine, Department of Medicine, Mayo Clinic, Rochester, MN 55905, USA
}

Correspondence to: Tamar Tchkonia, James L. Kirkland; email: tchkonia.tamar@mayo.edu, kirkland.james@mayo.edu Keywords: SARS-COV-2, senescence, toll like receptor 3, COVID-19

Received: August 20, $2021 \quad$ Accepted: September 14, 2021

Published: September 16, 2021

Copyright: (c) 2021 Tripathi et al. This is an open access article distributed under the terms of the Creative Commons Attribution License (CC BY 3.0), which permits unrestricted use, distribution, and reproduction in any medium, provided the original author and source are credited.

\section{ABSTRACT}

Senescent cells, which arise due to damage-associated signals, are apoptosis-resistant and can express a proinflammatory, tissue-destructive senescence-associated secretory phenotype (SASP). We recently reported that a component of the severe acute respiratory syndrome coronavirus 2 (SARS-CoV-2) surface protein, S1, can amplify the SASP of senescent cultured human cells and that a related mouse $\beta$-coronavirus, mouse hepatitis virus (MHV), increases SASP factors and senescent cell burden in infected mice. Here, we show that SARS-CoV-2 induces senescence in human non-senescent cells and exacerbates the SASP in human senescent cells through Toll-like receptor-3 (TLR-3). TLR-3, which senses viral RNA, was increased in human senescent compared to non-senescent cells. Notably, genetically or pharmacologically inhibiting TLR-3 prevented senescence induction and SASP amplification by SARS-CoV-2 or Spike pseudotyped virus. While an artificial TLR-3 agonist alone was not sufficient to induce senescence, it amplified the SASP in senescent human cells. Consistent with these findings, lung $\mathrm{p} 16^{\mathrm{INK} 4 a+}$ senescent cell burden was higher in patients who died from acute SARS-CoV-2 infection than other causes. Our results suggest that induction of cellular senescence and SASP amplification through TLR-3 contribute to SARS-CoV-2 morbidity, indicating that clinical trials of senolytics and/or SASP/TLR-3 inhibitors for alleviating acute and long-term SARS-CoV-2 sequelae are warranted. 


\section{INTRODUCTION}

The current COVID-19 pandemic has illuminated the vulnerability of the elderly and those with chronic diseases to increased SARS-CoV-2-mediated mortality. By August 2021, there had been over 207 million cases of SARS-CoV-2 and 4.3 million deaths worldwide (https://en.wikipedia.org/wiki/Template: COVID-19_pandemic_data accessed 08/16/2021). Those over age 65 accounted for $45 \%$ of patients hospitalized and $80 \%$ of those who died with SARSCoV-2 [1]. Recent studies have estimated that between $10-30 \%$ of patients experience persistent symptoms months after resolution of acute cases of COVID-19. These prolonged symptoms are referred to as postacute sequelae of SARS-CoV-2 infection (PASC) and might be a consequence of chronic inflammation induced during the acute phase of infection [2]. A mechanistic level of understanding of the short- and long-term effects of SARS-CoV-2 infection on cell and tissue function is urgently needed to tackle its acute and chronic adverse health outcomes.

We recently reported that senescent cells contribute to the pathogenesis of acute $\beta$-coronavirus infections [3]. The senescent cell fate entails essentially permanent cellcycle arrest with extensive changes in cell morphology and gene expression [4-6]. Senescence in many cell types is driven by damage/danger signals as well as metabolic insults, mechanical/shear forces, hypoxia, reactive oxygen species (ROS), repeated replication, oncogenes, telomere damage, and other stressors [7-10]. Senescence is established through transcription factor cascades that can include $\mathrm{p} 16^{\mathrm{INK} 4 \mathrm{a}} /$ retinoblastoma protein and/or $\mathrm{p} 53 / \mathrm{p} 21^{\mathrm{CIP} 1}$, which induce extensive changes in gene expression and organelle function, histone modifications, epigenomic remodelling, altered protein production, and profound morphologic and metabolic shifts $[11,12]$. Senescent cells are resistant to apoptosis, persistent, metabolically active, and mainly cleared by the immune system [13-15]. A majority of, but not all senescent cells can develop a senescenceassociated secretory phenotype (SASP), with release of inflammatory cytokines, chemokines, proteases, procoagulant and pro-fibrotic factors, bioactive lipids, other reactive metabolites, non-coding nucleotides, and extracellular vesicles [16-19]. The SASP can induce secondary senescence of neighboring previously nonsenescent cells and even of cells at a distance [20,21].

Senescence and the SASP have emerged as mechanisms that appear to contribute to aging phenotypes and multiple chronic conditions and diseases, even in younger individuals (e.g., in those with obesity/diabetes, cardiac, lung, and kidney disorders, arthritis, cancers, osteoporosis, or neurocognitive or immunological dysfunction), and can underlie adverse effects due to certain drugs and treatments, such as chemotherapy or radiation [5, 22-32]. Many of the clinical conditions linked to cellular senescence share features with complications associated with sequelae of COVID-19. Both can be associated with cognitive dysfunction, frailty/weakness, arthritis and arthralgias, cardiac conditions, and lung dysfunction and fibrosis, among others $[4,5,23,24,27,29,31,33-35]$. Additionally, factors such as IL-6, IL-8, and IP-10 that are SASP components appear to predict the severity of SARSCoV-2 infection [36]. These factors may also contribute to prolonged disease, hyper-inflammation/cytokine storm, acute respiratory distress (ARDS), and multi organ failure.

Incoming viral pathogens are detected by the innate immune system through dedicated sensors, Toll-Like Receptors (TLRs), which recognize pathogen-associated molecular patterns and engage innate immune responses. Although SASP-related cytokines are a critical component of the innate immune response and aid in clearing viral infections, dysregulated release of proinflammatory cytokines may lead to cytokine storm, which can result in severe damage to host tissues and organs. Here, we examined innate immune responses to SAR-CoV-2 and links to cellular senescence. We found that both a Spike pseudotyped virus (pseudovirus) and the genuine SARS-CoV-2 virus can induce senescence in human cells. Furthermore, the senescent cell SASP was amplified by TLR-3-dependent signaling. Clinical trials appear be warranted to ascertain if senolytics, agents that selectively eliminate senescent cells, senomorphics, which inhibit the SASP, and/or TLR-3 inhibitors can alleviate acute or long-term sequelae of SARS-CoV-2 infection.

\section{RESULTS}

\section{Increased TLR-3 expression in senescent cells}

TLRs are major innate immune sensors whose expression varies depending on cell type [37]. Therefore, we analyzed if TLRs are present on senescent cells. TLR-1, -3 , and -4 were more highly expressed in radiation-induced senescent $v s$. non-senescent human preadipocytes (Figure 1A). Among other ligands, TLR-1 binds gram-positive bacterial antigens, TLR-3 binds viral RNA, and TLR-4 binds lipopolysaccharide [38]. Also, TLR-3 mRNA was increased in senescent human kidney endothelial cells compared to non-senescent controls (Figure 1B). TLR-3 protein levels were higher in radiation-induced senescent human kidney endothelial cells than non-senescent controls (Figure 1C). Thus, TLR-3, a sensor of viral RNA, can be present in increased abundance on senescent cells. 
Pseudovirus induces senescence in non-senescent human kidney endothelial and lung epithelial cells

We previously reported that mouse coronavirus induces senescence in vivo (see Figure 3B) [3]. To examine whether exposure of senescent cells to SARS-CoV-2 might induce senescence through TLR-3, non-senescent human cells were exposed to vesicular stomatitis virus (VSV) encoding SARS-CoV-2 Spike instead of its native G Glycoprotein (VSVdG*Spike), a pseudovirus that simulates the presence of SARS-CoV-2 but is safer to handle [39]. Expression of the cellular senescence markers $\mathrm{p} 16^{\mathrm{INK} 4 \mathrm{a}}$ and $\mathrm{p} 21^{\mathrm{CIP} 1}$ was increased by exposing non-senescent human kidney endothelial (Figure 2A) and lung epithelial cells (Figure 2B) to this pseudovirus for 14 days. The TLR-3 antagonist, (R)-2-(3-chloro-6fluorobenzo[b]thiophene-2-carboxamido)-3-phenylpropanoic acid, counteracted this induction of senescence markers by the pseudovirus in both human kidney endothelial and lung epithelial cells (Figure 2A, 2B).
Exposure to a TLR-3 agonist, polyinosine-polycytidylic acid (Poly I:C), for 1 week tended to induce increase in $\mathrm{p} 16^{\mathrm{INK} 4 \mathrm{a}}$ and $\mathrm{p} 21^{\mathrm{CIP} 1}$ expression in human non-senescent preadipocytes, but not significantly (Figure 2C). Taken together, these results indicate that pseudovirus sensed by TLR-3 is sufficient to promote senescence.

\section{Pseudovirus amplifies the SASP of senescent human cells via TLR-3}

Sensing of a virus by TLR-3 usually induces proinflammatory cytokines, including IL-6, MCP-1, and TNF $\alpha$. To assess whether SARS-CoV-2 sensing by TLR-3 promotes the release of pro-inflammatory cytokines and amplifies the SASP, senescent human preadipocytes (Figure 3A) and senescent kidney endothelial cells (Supplementary Figure 2) were exposed to the pseudovirus for $96 \mathrm{hrs}$ as well to non-senescent control cells. After exposure, pseudovirus-exposed senescent cells had increased expression of the key SASP
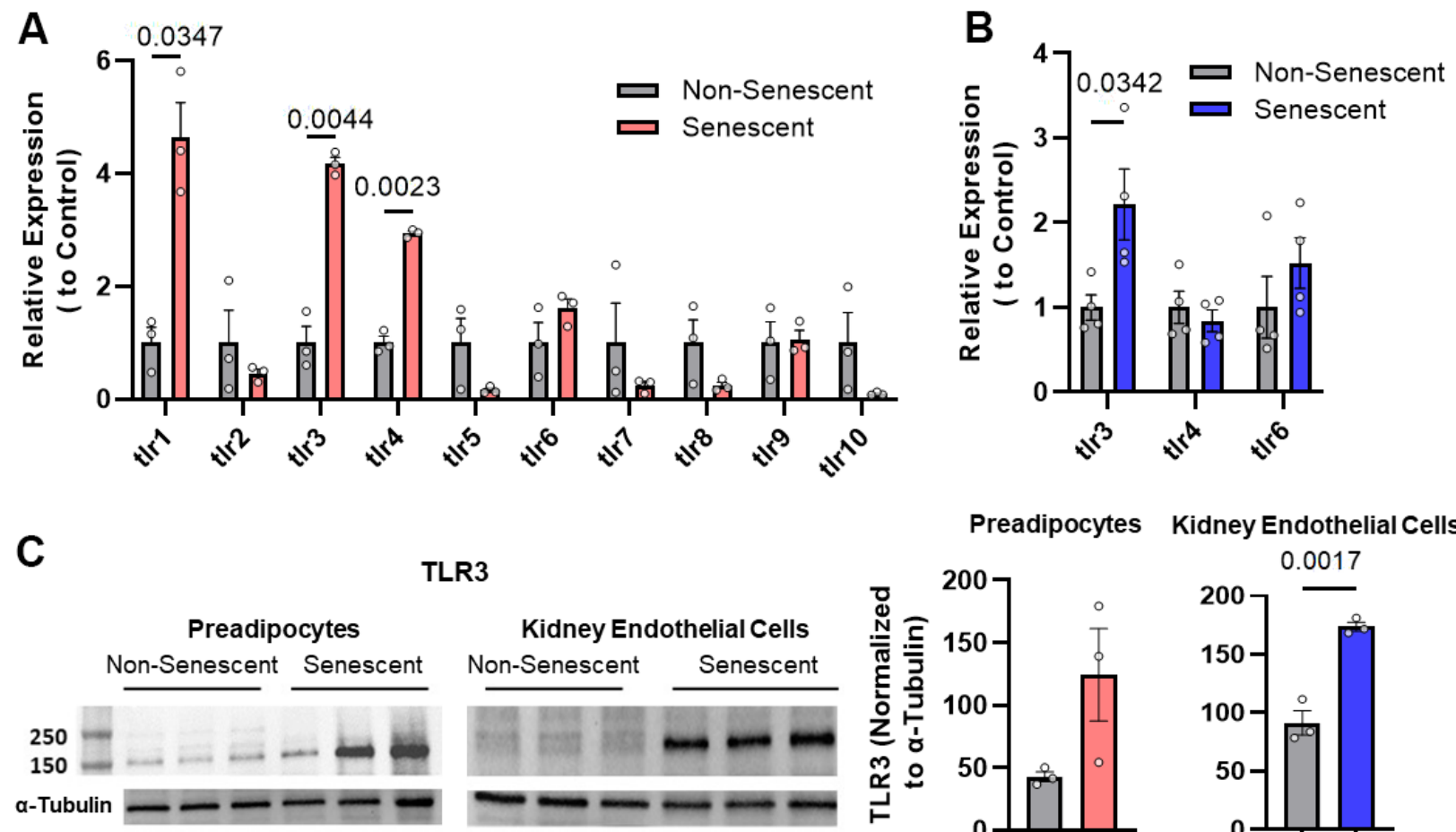

TLR3

Preadipocytes Kidney Endothelial Cells
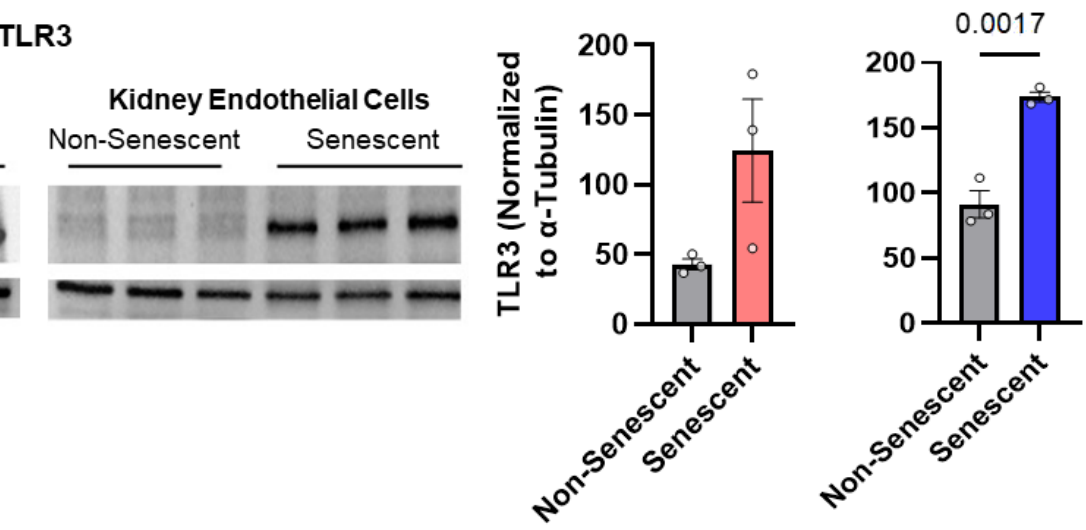

Figure 1. Toll-like receptor-3 (TLR-3) is increased in senescent vs. non-senescent human kidney endothelial cells and preadipocytes. (A) TLR expression (rtPCR) in radiation-induced senescent vs. non-senescent human preadipocytes $(n=3)$. (B) TLR ( $r$ PCR) in radiation-induced senescent human kidney endothelial cells $(n=4)$ vs. non-senescent cells. Data are expressed as a function of non-senescent cells; mean +/- SEM, paired (A), unpaired (B), 2-tailed Student's t-tests. (C) TLR-3 protein (Western blots) in non-senescent and senescent preadipocytes $(n=3)$ and kidney endothelial cells $(n=3)$ with tubulin as loading control (optical density of TLR-3 as a function of $\alpha$-tubulin [\%]). Data are expressed as a function of non-senescent cells; mean +/- SEM, paired (preadipocytes), unpaired (kidney endothelial cells), 2-tailed Student's t-tests. 
A

Kidney Endothelial Cells
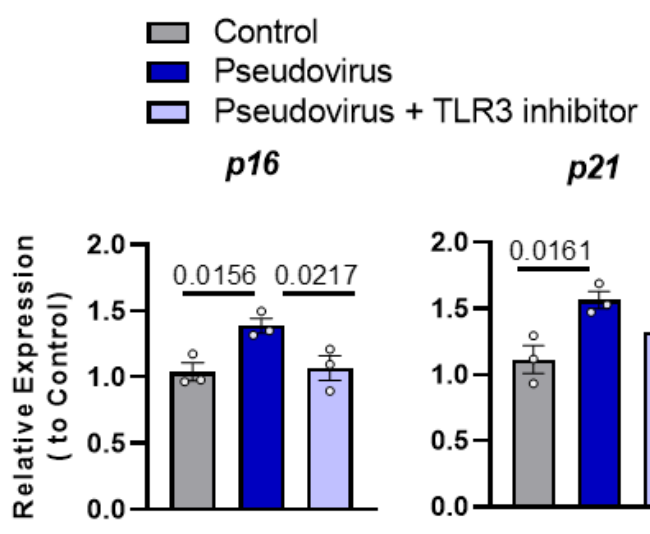

il1 $\beta$

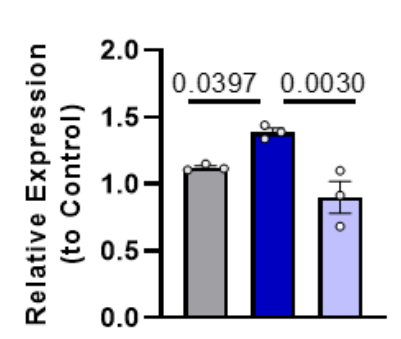

il8

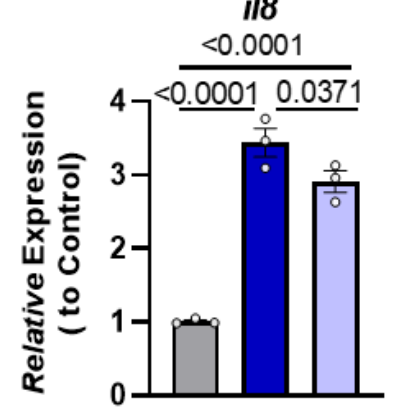

C

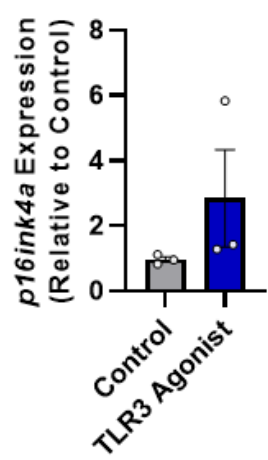

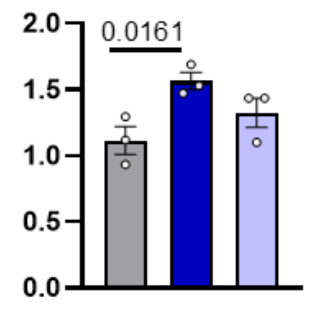

il6

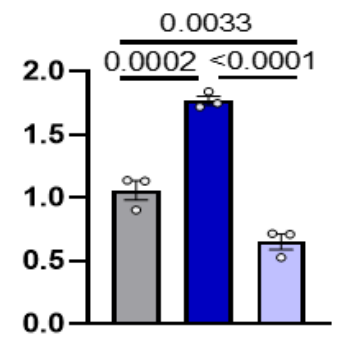

ip10
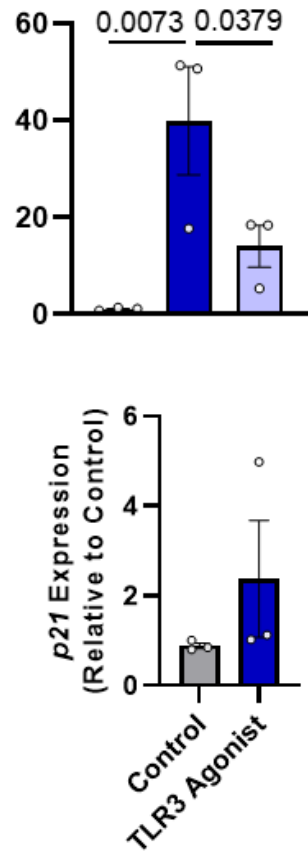

B Lung Epithelial Cells
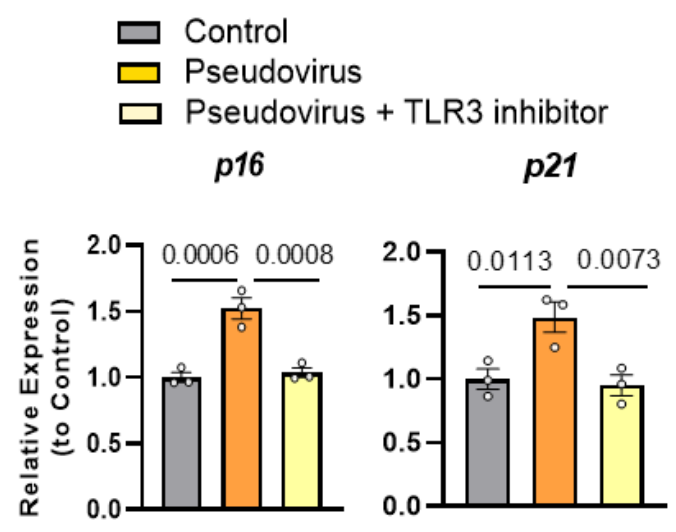

il6
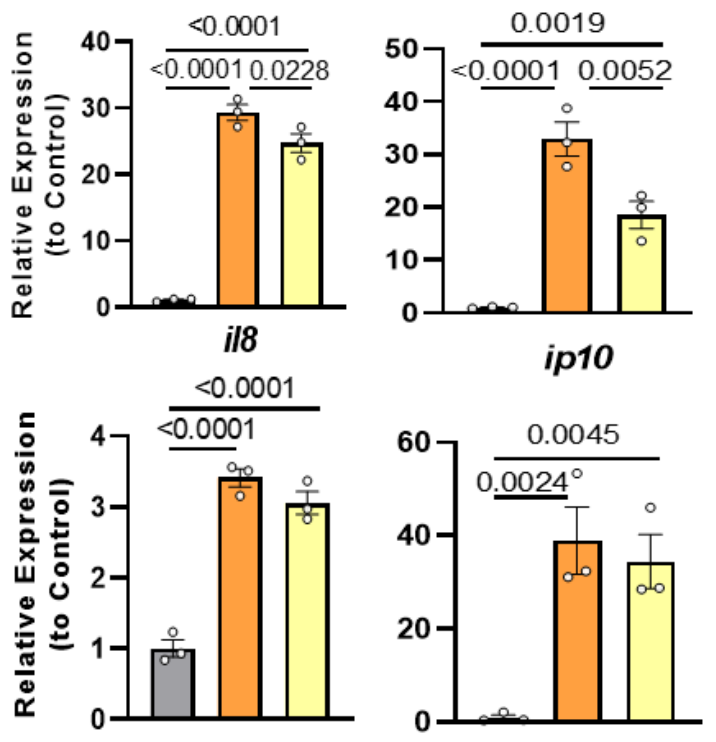

D
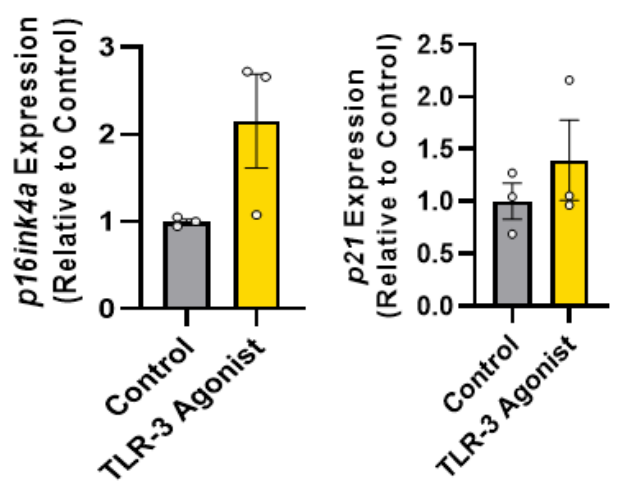

Figure 2. Pseudovirus exposure increases senescence markers in non-senescent cells; these increases in markers were attenuated by TLR-3 inhibitor. (A) Non-senescent kidney endothelial cells and (B) human lung epithelial cells had higher expression of senescence markers and SASP factors upon treatment with pseudovirus, while using TLR-3 inhibitor decreased their expression. Cells were exposed to the pseudovirus in the presence of TLR-3 inhibitor or vehicle (control) for 14 days. (C, D) Activating TLR-3 was not sufficient to induce senescence: TLR-3 agonist did not induce senescence as extensively as the pseudovirus. Non-senescent kidney endothelial (C) and lung epithelial cells (D) were treated with the TLR-3 agonist Poly I:C (2 and $10 \mu \mathrm{g} / \mathrm{ml}$, respectively), for 7 days or pseudovirus, when senescence markers and SASP factor expression were measured. Data are expressed as a function of untreated non-senescent cells; mean +/SEM, 1-way ANOVA and post hoc comparisons with Fisher's LSD (A, B) and unpaired Student's t-tests (C, D). 

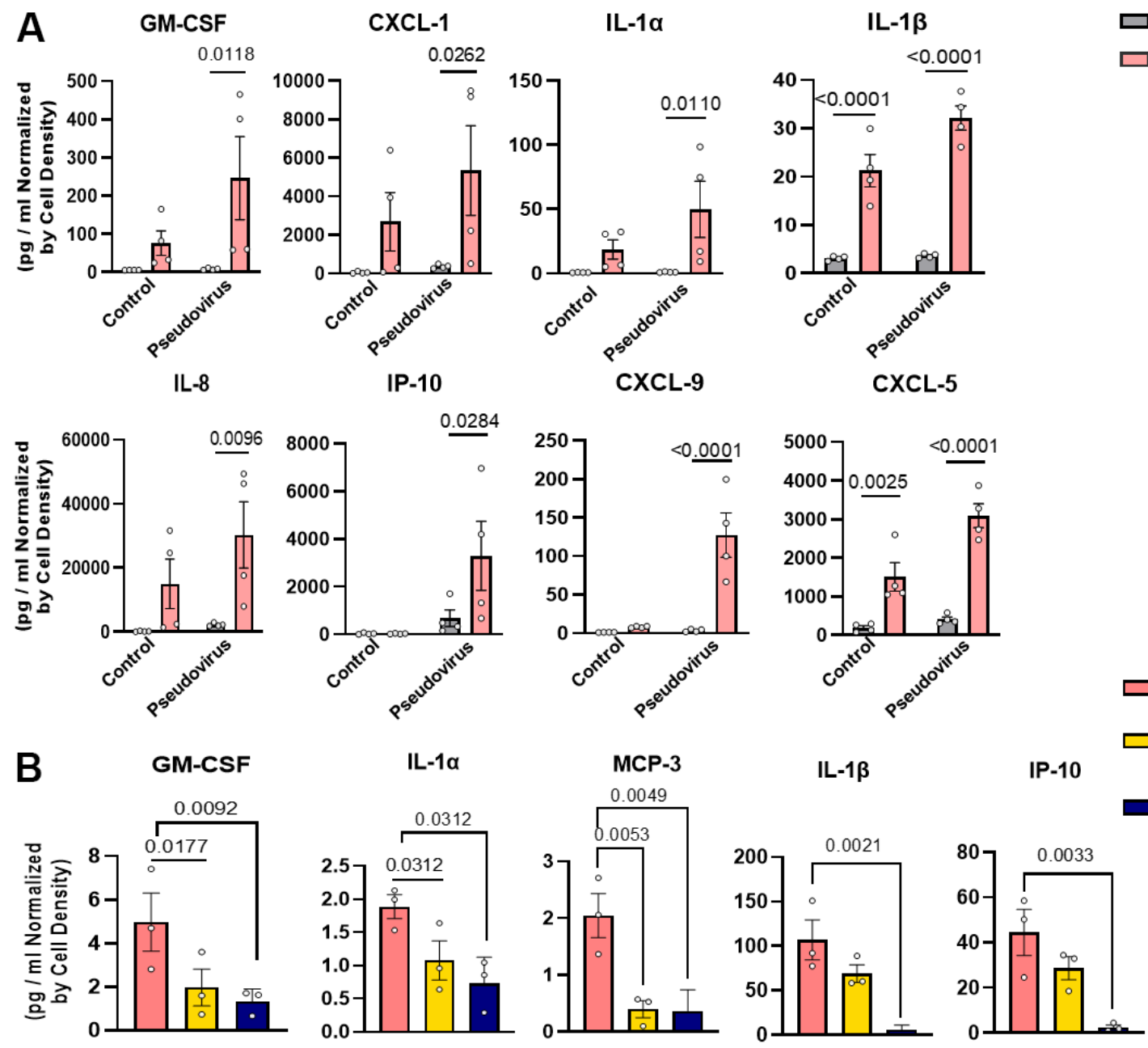

Pseudovirus TLR3 si-RNA + Pseudovirus

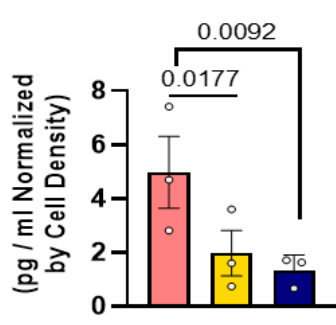

C

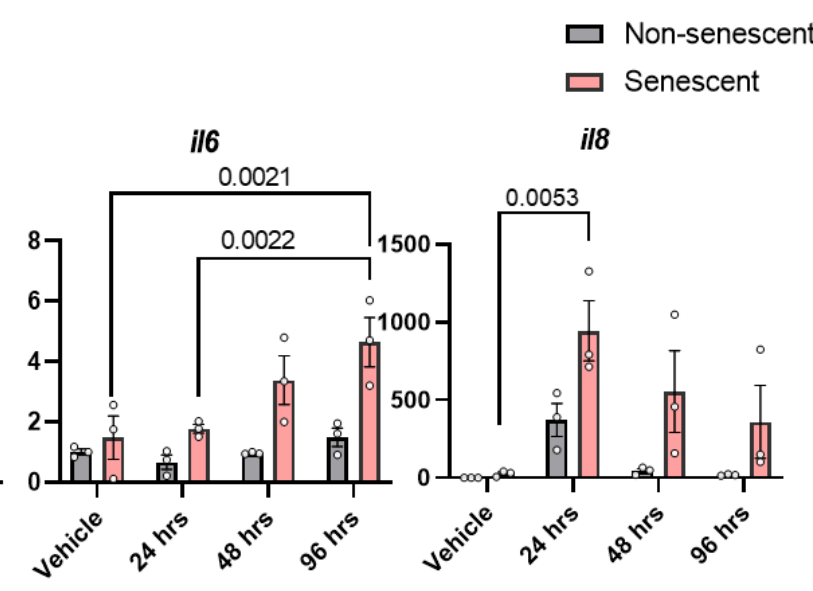

Figure 3. Pseudovirus amplifies the SASP in senescent preadipocytes and genetically or pharmacologically inhibiting TLR-3 attenuates this SASP amplification. (A) SASP factors were assayed in senescent and non-senescent preadipocytes $(n=4)$ treated with pseudovirus for 96 hrs. Data are shown as a function of cell number; mean +/- SEM, 2-way repeated measures ANOVA. (B) Senescent cells

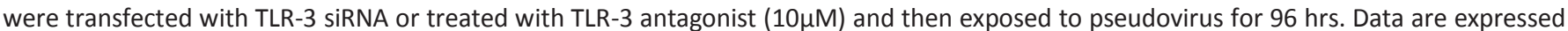
as a function of untreated senescent cells; mean +/- SEM, repeated 1-way ANOVA and post hoc pairwise comparisons Fischer's LSD. (C) TLR-3 agonist increases SASP factor expression in senescent (but not non-senescent) human preadipocytes. Senescent and non-senescent preadipocytes were exposed to Poly I:C for 24, 48, or $96 \mathrm{hrs}$. and analyzed for SASP factors (rtPCR). Data are expressed as a function of untreated senescent cells; mean +/- SEM, repeated 2-way ANOVA and post hoc pairwise comparison Tukey's HSD. All other significant $p$ values are listed in Supplementary Table 1. 
factors, IL-1 $\alpha$, IL-1 $\beta, \quad$ IL-8, and chemokine-like CXCL5, compared to non-senescent preadipocytes. This amplification was attenuated by decreasing TLR-3 expression using siRNAs or by treatment with a TLR-3 antagonist (Figure 3B and Supplementary Figure 1). This suggests that TLR-3 activation is sufficient for the pseudovirus to amplify the pro-inflammatory SASP of pre-existing senescent cells.

To determine if senescent cells respond directly to TLR-3 activation, radiation-induced senescent human preadipocytes $v s$. non-exposed senescent controls were exposed to the TLR-3 agonist for 24, 48, or $96 \mathrm{hrs}$. (Figure 3C). The TLR-3 agonist amplified expression of several cytokines, including IL-1 $\alpha$, IL-1 $\beta$, IL- 6 , and IL8. Expression of these cytokines was higher in exposed senescent cells than cells not exposed to the TLR-3 agonist. Remarkably, the increase in SASP factor expression appeared to be greater after TLR-3 agonist exposure of senescent than non-senescent cells, suggesting that senescent cells have an amplified inflammatory response to RNA-viral PAMPs. Together with the above data showing that a TLR-3 antagonist prevents amplification of the SASP by pseudovirus, these experiments with the TLR-3 agonist indicate that signaling through TLR-3 is both necessary and sufficient for SARS-CoV-2 amplification of the SASP.

\section{Genuine SARS-CoV-2 amplifies the SASP of senescent preadipocytes cells via TLR-3}

To test if the effects of the pseudovirus reflect the impact of genuine SARS-CoV-2, senescent human preadipocytes were exposed to SARS-CoV-2 for $48 \mathrm{hrs}$. SARS-CoV-2 did not infect or productively replicate in preadipocytes (Figure 4A). In line with results using pseudovirus or TLR-3 agonists, senescent cells exposed to genuine SARS-CoV-2 virus had an amplified SASP response, characterized by increased IL-1 $\alpha$, IL- $1 \beta$, IL-6, IL-8, and GMCSF mRNA levels (Figure 4B). Silencing of TLR-3 expression prevented induction of these cytokines, while silencing of TLR-4 had little if any attenuating effect (Figure 4B and Supplementary Figure 1). These results indicate that genuine SARS-CoV-2 external to senescent preadipocytes is sensed in a TLR3-dependent manner, further exacerbating their proinflammatory SASP.

\section{Lung p16 ${ }^{\mathrm{INK} 4 \mathrm{a}+}$ senescent cell burden is greater in patients dying from acute SARS-CoV-2 than from other causes}

To investigate if SARS-CoV-2 infection is associated with induction of senescence, we compared $\mathrm{p} 16^{\mathrm{INK} 4 \mathrm{a}}$ expression in lungs from 10 patients who had died from SARS-CoV-2 (age $76 \pm 13$ years; mean \pm SD; 3 females,
7 males) to 6 controls (age $78 \pm 19.5$ years; 2 females, 4 males) who did not have COPD, asthma, or other pulmonary diseases (Mayo Clinic Tissue Registry; Mayo Clinic IRB \#21-001392) as shown in Supplementary Tables 1 and 2. We found increased numbers of $\mathrm{p} 16^{\mathrm{INK} 4 \mathrm{a}}$ positive cells in the lungs of patients who had died from SARS-CoV-2 (Figure 5), consistent with the possibility that SARS-CoV-2 infection can induce cellular senescence.

\section{DISCUSSION}

We previously reported that SARS-CoV-2 surface antigen Spike-1 protein (S1), which signals through ACE2 receptors, can cause amplification of the tissuedestructive, pro-inflammatory SASP of already senescent human cells [3]. Here, we show that SARSCoV-2 Spike pseudotyped VSV can cause nonsenescent cells to become senescent through TLR-3 in kidney endothelial and lung epithelial cells. However, in future studies other cells types also need to be assessed. Additionally, the pseudovirus and genuine SARS-CoV-2 amplified the SASP through TLR-3, with senescent cells becoming more pro-inflammatory than non-senescent cells after viral exposure. Expression of TLR-3 mRNA and protein was higher in senescent than non-senescent cells. Genuine SARS-CoV-2 did not replicate to detectable levels in either senescent preadipocytes or non-senescent preadipocytes, yet the virus amplified the SASP in the former. This is consistent with the increased abundance of TLR-3 receptors on senescent vs. non-senescent cells contributing to SASP amplification. Furthermore, TLR3 antagonists or depletion prevented senescence induction as well as SASP amplification by the pseudovirus and genuine SARS-CoV-2, further indicating a role for TLR-3. A TLR-3 activator amplified the SASP, paralleling effects of viral exposure, suggesting that TLR-3 signaling is both necessary and sufficient for SASP amplification by SARS-CoV-2. This exacerbation of the SASP by SARS-CoV-2 through TLR-3 might further contribute to the SASP induction by $\mathrm{S} 1$ that we reported previously in multiple cells to test further the generalizability of the mechanisms we reported [3]. Key findings with the pseudovirus were recapitulated with genuine SARS-CoV-2. Also, more highly $\mathrm{p} 16^{\mathrm{INK} 4 \mathrm{a}}$-expressing cells were present in lungs of patients who had died from SARS-CoV-2 than patients dying from other causes, indicating an increased senescent cell burden in SARS-CoV-2 patients. However, more senescent markers, e.g., p21 ${ }^{\mathrm{CIP} 1}$, will need to be examined in patients' lungs, since $\mathrm{p} 16^{\mathrm{INK} 4 \mathrm{a}}$ expression can also be increased in nonsenescent cells, such as activated macrophages [40]. Formation of new senescent cells, coupled with SASP amplification, could contribute to the markedly greater 
morbidity and mortality from SARS-CoV-2 infection in patients with high pre-existing senescent cell burden than young, previously healthy patients. This includes elderly SARS-CoV-2 patients as well as younger patients with cellular senescence-linked conditions, such as obesity, diabetes, chronic respiratory, cardiovascular, and renal diseases, cancers, or a history of chemotherapeutic or radiation treatment, among others $[5,24,25,31,41]$.

It has been appreciated for some time that the SASP can be attenuated by "senomorphic" agents, such as rapamycin or metformin [42]. However, it has only recently become apparent that the SASP can be amplified
A

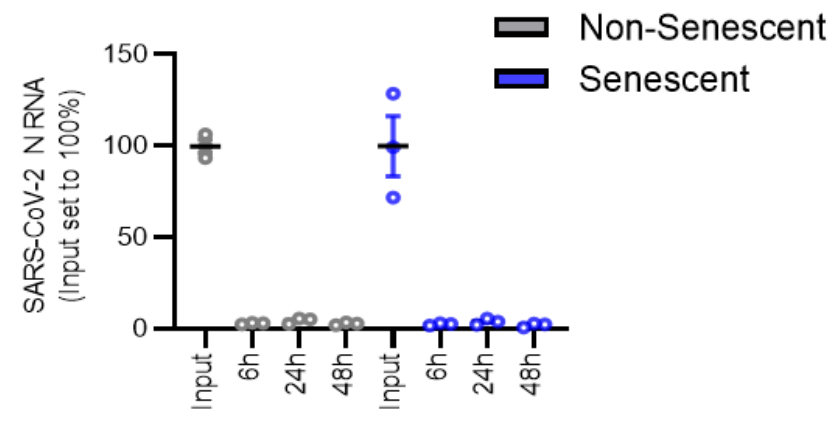

B

$\square$ Control

$\square$ SARS-COV-2+ Scrambled si-RNA

$\square$ SARS-COV-2+ TLR-3 si-RNA

ש SARS-COV-2+ TLR-4 si-RNA

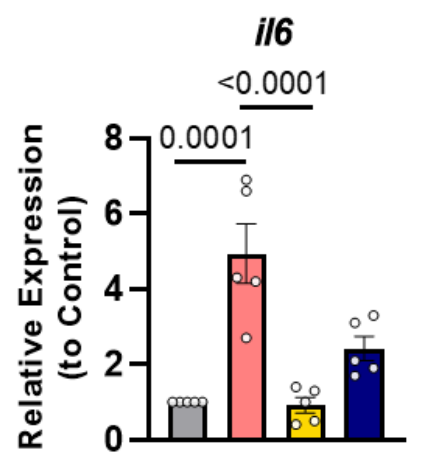

il8

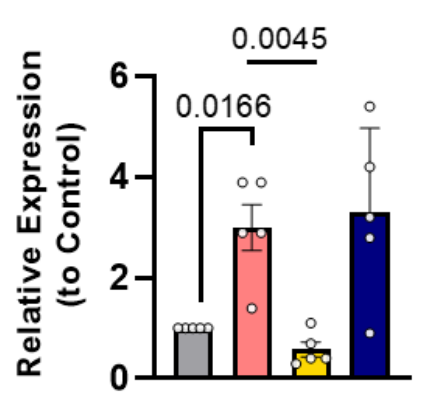

il1a

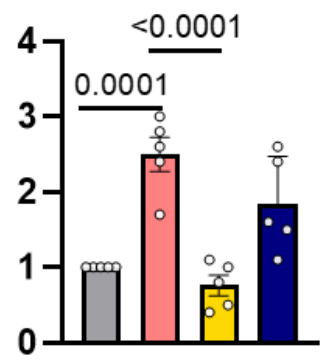

gmcsf

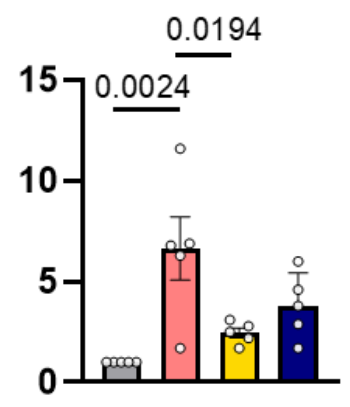

il1 $\beta$

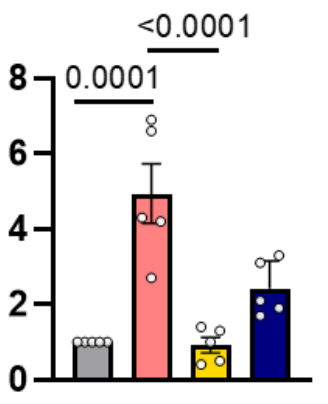

ip10

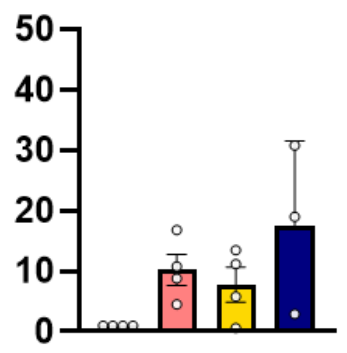

Figure 4. SARS-CoV-2 amplifies the SASP of senescent preadipocytes without infecting them. (A) Senescent and non-senescent preadipocytes were exposed to SARS-CoV-2 for the indicated times and assayed for infection by qPCR. (B) Senescent preadipocytes were treated with SARS-CoV-2 and the SASP was assayed $82 \mathrm{hrs}$. later by qPCR. Data are expressed as a function of untreated senescent cells; mean +/- SEM, repeated 1-way ANOVA and post hoc comparison pairwise Tukey's HSD. All other significant $p$ values are listed in Supplementary Table 1. 
by signals like PAMPs, such as lipopolysaccharide or S1 antigen, as predicted by our SASP "Amplifier/ Rheostat Hypothesis" [3]. The finding that SARS-CoV2 exacerbates the SASP through TLR-3 is consistent with this hypothesis, which may partly explain the increased morbidity and mortality due to hyperinflammation and tissue destruction in older and chronically-ill individuals compared to previously healthy, younger SARS-CoV-2-infected individuals. Also, consistent with this hypothesis, we recently reported that reducing senescent cell abundance genetically or pharmacologically (with senolytic agents) in old mice infected with a $\beta$-coronavirus related to SARS-CoV-2, mouse hepatitis virus (MHV), reduces their higher risk for cytokine storm and mortality than young mice [3]. Potentially, the Amplifier/Rheostat Hypothesis accounts for the increased morbidity and mortality in patients with increased pre-existing senescent cell burden from other types of infections, although further testing is needed.

Interactions between senescent cells, their SASP, and immune cells likely contribute to the impact of senescent cells on SARS-CoV-2 morbidity and mortality [14]. Immune cells can act to increase senescent cell abundance. Activated neutrophils, which accumulate extensively in lungs of severely ill SARSCoV-2 patients [43], have the capacity to induce nonsenescent cells to become senescent [10], potentially adding to the senescent cell burden caused by SARSCoV-2 through TLR-3 dependent signalling.

Senescent cells are resistant to apoptosis [13] and are mainly removed by the immune system [14]. We previously found that the SASP causes spread of senescence to normal cells, not only locally but also at a distance [20]. These observations led us to propose the
"Threshold Theory of Senescent Cell Burden". This theory, if true, suggests that above a threshold abundance, senescent cells persist and even increase in number because the rate of formation of new senescent cells exceeds senescent cell removal by the immune system. Reaching this threshold would depend on the sum of pre-existing and newly formed senescent cells. To confirm whether such a threshold model would be mathematically tenable given available data and information remains to be evaluated. New senescent cells induced by viral RNA, on top of senescent cell spread from SASP amplification due to virally-induced TLR-3 activation, S1-induced ACE2 stimulation, and increased ROS, could result in surpassing the senescent cell threshold, leading to feed-forward increases in senescent cell burden and resulting morbidity and mortality. Adding to the above, a high burden of senescent cells can impair normal immune system function [14].

A persisting or increasing burden of senescent cells, the SASP, and/or SASP amplification could combine to contribute to both immediate and long-term morbidity due to current or previous SARS-CoV-2 viremia. Consistent with this possibility, transplanting even a small number of senescent cells causes complications resembling those of coronavirus infection in mice, including frailty, weakness, decreased activity, and increased mortality [20]. Hence, increased abundance of senescent cells might contribute to the brain fog/anxiety, physical inactivity/lethargy/muscle weakness/frailty, lung fibrosis/dyspnea, and arthritis/generalized pain symptoms that can persist after acute SARS-CoV-2 infection, the so called post-acute sequelae of COVID-19. Senescent cell burden may even account, in part, for the frailty/ accelerated aging-like state that progresses four times faster in older nursing home residents vs. uninfected
A Control

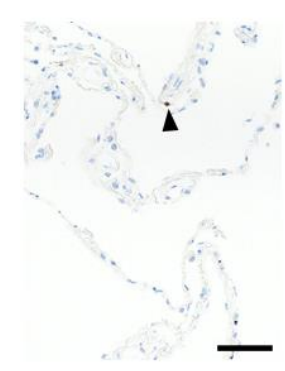

COVID-19

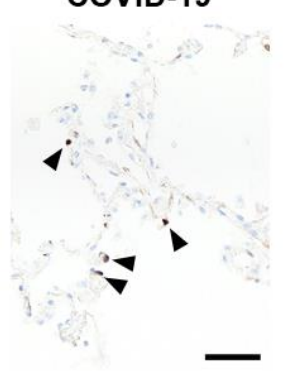

B

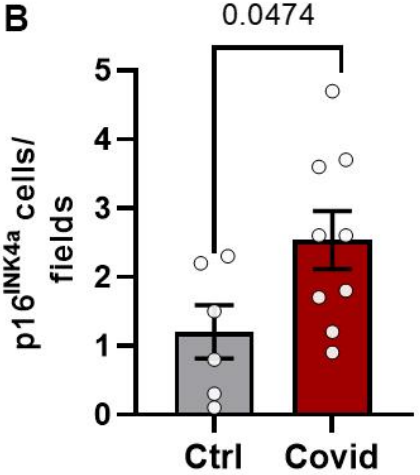

Figure 5. Lung p16INK4a+ senescent cell burden is greater in patients dying from acute SARS-CoV-2 than other causes. Lung tissue from patients who died from SARS-CoV-2 $(n=9)$ were compared to controls $(n=6)$ who died from other causes without lung disease (see Supplementary Tables 2, 3). (A) Paraffin-embedded lung autopsy tissue was sectioned and stained for p16INK4a by immunohistochemistry (black arrowheads). (B) Fifteen fields of alveolar tissue were randomly selected and counted. Mean +/- SEM, unpaired 2-tailed Student's t-test. 
residents for months after SARS-CoV-2 viremia has resolved [44]. Based on these considerations, a clinical study has commenced to test if senescent cell burden is increased in patients with PASC $v s$. age-matched controls (Cellular Senescence and COVID-19 Long-Hauler Syndrome; clinicaltrials.gov identifier NCT04903132).

The effects of SARS-CoV-2 on SASP activation and induction of cellular senescence considered here raise a number of questions that indicate directions for further research, particularly regarding potential clinical interventions to delay, prevent, and treat short- and longterm complications of SARS-CoV-2 viremia. One such class of drugs is senolytics, agents that selectively eliminate senescent cells. Senolytics transiently disable the senescent cell anti-apoptotic pathway (SCAP) network that shields senescent cells from their own SASP and that allows them to survive despite their killing cells around them and causing tissue damage [45-50]. We recently reported that morbidity and mortality in old mice infected with $\beta$-coronavirus, MHV, are attenuated by the senolytics, Fisetin and the combination of Dasatinib and Quercetin [3]. Clinical trials of senolytics for SARSCoV-2 are already underway, including a SARS-CoV-2 acute hospital trial (COVID-FISETIN: Pilot in SARSCoV-2 of Fisetin to Alleviate Dysfunction and Inflammation; NCT04476953), a skilled nursing facility trial (COVID-FIS, A Study of Fisetin for Skilled Nursing Facility Residents with COVID-19; NCT04537299), and an outpatient trial (COVFIS-HOME: COVID-19 Pilot Study of Fisetin to Alleviate Dysfunction and Disease Complications; NCT04771611). Senomorphics, such as metformin or agents related to rapamycin, such as sirolimus, offer an alternative way to attenuate the SASP [42]. Trials with senomorphics are also underway (e.g., metformin: NCT04510194 and NCT04727424; sirolimus: NCT04341675 and NCT 04948203). Yet another option might be to conduct trials with TLR-3 antagonists, which have been used in pre-clinical studies of SARS-CoV-2 infection [51]. These agents, which have been in clinical trials as immuno-modulators and adjuvants to enhance vaccine effectiveness, have not for the most part advanced past early phase trials [52]. While TLR-3 antagonists may prove to be of use for treating SARS-CoV-2, this might only be during a narrow window early in the course of infection because, based on the findings reported here, these agents would mainly be effective during active viremia before senescent cell abundance has been increased.

\section{MATERIALS AND METHODS}

\section{Cell culture}

Preadipocytes were isolated from abdominal subcutaneous fat biopsies obtained from subjects under- going gastric bypass surgery. All subjects gave informed consent. The protocol was approved by the Mayo Clinic Institutional Review Board for Human Research. Cells were isolated, cultured, and were made senescent as previously described [53] and corresponding non-senescent were used as controls whenever required. Human primary renal glomerular endothelial cells (Science Cell, Cat \#4000, Carlsbad, CA. USA) and human small airway epithelial cells (Cat\# CC-2547, Lonza) were purchased and cultured following the manufacturer's instructions. Human preadipocytes and kidney endothelial cells were made senescent by $20 \mathrm{~Gy}$ irradiation and experiments were performed after 30 days and 21 days, respectively.

\section{Reagents}

Cells were treated with following reagents as indicated in the figures: 1) polyinosine-polycytidylic acid (Cat \#tlrlpic-5, Invivogen, San Diego, CA, USA), 2) (R)-2-(3chloro-6-fluorobenzo[b]thiophene-2-carboxamido)-3phenylpropanoic acid, Toll-Like Receptor-3/double strand RNA complex inhibitor (Cat\# 614310-10MG, Burlington, MA, USA), and 3) pseudovirus (Cat \#B2000052, Brainvta, Wuhan, China).

\section{RNA extraction and rtPCR}

For most studies, RNA isolation and rtPCR were performed using Trizol as in $[54,55]$. Cells were washed with PBS, then Trizol and chloroform were added to each sample. Samples were centrifuged to separate the aqueous layer. RNA was purified using columns (Qiagen Kit Cat\#74104) according to the manufacturer's instructions. Concentration and purity of samples were assayed using a Nanodrop spectrophotometer. Each cDNA sample was generated by reverse transcription using 1-2000 ng RNA following the manufacturer's recommended protocol (High-capacity cDNA Reverse Transcription Kit; Cat \#4368813, Thermo Fisher Scientific, Waltham, MA, USA). A standard reverse transcription program was used $\left(10 \mathrm{~min}\right.$. at $25^{\circ} \mathrm{C}, 120$ min. at $37^{\circ} \mathrm{C}, 5 \mathrm{~min}$. at $85^{\circ} \mathrm{C}$, held at $4^{\circ} \mathrm{C}$ ). TBP was used as a control for gene expression analysis. For the experiments related to coronavirus, we used following method for rtPCR. SARS-CoV-2 nucleoprotein (N) RNA levels were assayed in supernatants of infected samples 48 hrs. post-infection. Forward (HKU-NF): 5'TAA TCA GAC AAG GAA CTG ATT A-3' and reverse primers (HKU-NR): 5'-CGA AGG TGT GAC TTC CAT G-3'; Probe (HKU-NP): 5'-FAM-GCA AAT TGT GCA ATT TGC GG-3'TAMRA) were from Biomers (Ulm, Germany). IL-6, IL-8, IP-10, CSF2, IL$1 \alpha$, IL-1 $\beta, \mathrm{p} 16^{\mathrm{INK} 4 \mathrm{a}}$, and $\mathrm{p} 21^{\mathrm{CIP} 1}$ primers and probes (TaqMan) were from Thermo Fisher Scientific. RNA levels were determined in cells collected from SARS- 
CoV-2-infected samples $82 \mathrm{hrs}$. post-infection. Total RNA was isolated from cells or supernatants using a Viral RNA Mini Kit (\#52904, Qiagen, Hilden, Germany) according to the manufacturer's instructions. rtPCR was performed according to the manufacturer's instructions using TaqMan Fast Virus 1-Step Master Mix (Cat\#4444436, Thermo Fisher Scientific) and a OneStepPlus Real-Time PCR System (96-well format, fast mode). Synthetic SARS-CoV-2-RNA (Cat\#Q87194, Twist Bioscience, South San Francisco, CA, USA) was used as a quantitative standard to determine viral copy numbers. All reactions were run in duplicate. mRNAs were expressed as a function of GAPDH primer/probe sets (Cat\#4310884E, Thermo Fisher Scientific). Data were analyzed by the $\Delta \Delta \mathrm{Ct}$ method.

Primers used are listed below.

\begin{tabular}{lc}
\hline Gene name & Primers \\
\hline TLR1 & Hs00413978_m1 \\
TLR2 & Hs02621280_s1 \\
TLR3 & Hs01551079_g1 \\
TLR4 & Hs00152939_m1 \\
TLR5 & Hs01920773_s1 \\
TLR6 & Hs01039989_s1 \\
TLR7 & Hs01933259_s1 \\
TLR8 & Hs07292888_s1 \\
TLR9 & Hs00370913_s1 \\
TLR10 & Hs01935337_s1 \\
TBP & Hs00427620_m1 \\
P16 & Hs00923894_m1 \\
P21 & Hs00355782_m1 \\
IL-1 $\alpha$ & Hs00174092_m1 \\
IL-1 $\beta$ & Hs01555410_m1 \\
Il-6 & Hs00174131_m1 \\
IL-8 & Hs00174103_m1 \\
IP-10 & Hs00171042_m1 \\
CSF2 & Hs00929873_m1 \\
\hline
\end{tabular}

\section{siRNA knockdown}

Cells were transfected with the indicated siRNAs using RNAi max reagent (Cat\#13778075; Thermo Fisher Scientific) as in [55]. Briefly, cells were transfected in antibiotic-free media in 6 well plates. $9 \mu 1$ RNAi max/well were mixed in $150 \mu$ l OPTI-mem media and $6 \mu 110 \mu \mathrm{M}$ siRNA in $150 \mu 1$ of OPTI-MEM medium in a separate Eppendorf tube. The two tubes were mixed and incubated for 5 mins. $250 \mu \mathrm{l}$ of the mixture were added to wells. The following siRNAs were purchased from Thermo Fisher Scientific): TLR-3 siRNA (Assay ID: 107054) and TLR-4 siRNA (Assay ID: s-14195).

\section{Western blots}

Cells or tissues were homogenized in RIPA buffer (Cat \#89900, Thermo Fisher Scientific) with protease inhibitors (Cat\# 78430, Thermo Fisher Scientific). Proteins were loaded on SDS-PAGE gels and transferred to immuno-blot PVDF membranes (Biorad, Hercules; CA, USA). ECL Western Blotting Substrate (Pierce; cat \#32106, Rockford IL, USA) was used to develop signals. TLR-3 (catalog \#6961) and $\alpha$-tubulin (catalog \#2144) antibodies were purchased from Cell Signaling. Data were quantified using the optical densities of the specified proteins as a function of $\alpha$ tubulin.

\section{SARS-CoV-2 stock production}

BetaCoV/France/IDF0372/2020 was propagated on Vero E6 infected at a multiplicity of infection (MOI) of 0.003 in serum-free medium containing $1 \mu \mathrm{g} / \mathrm{ml}$ trypsin, as previously described [56]. Briefly, the cells were inoculated for $2 \mathrm{hrs}$. at $37^{\circ} \mathrm{C}$ before the inoculum was removed. The supernatant was harvested 48 hrs. postinfection upon visible cytopathic effect. To remove debris, the supernatants were centrifuged for $5 \mathrm{~min}$. at $1,000 \mathrm{xg}$, then aliquoted and stored at $-80^{\circ} \mathrm{C}$.

\section{Plaque-forming unit assays}

Plaque-forming unit (PFU) assays were performed as previously described [57]. Briefly, SARS-CoV-2 stocks were serially diluted and confluent monolayers of Vero E6 cells infected. After incubation for $2 \mathrm{hrs}$. at $37^{\circ} \mathrm{C}$ with shaking every $20 \mathrm{~min}$., the cells were overlaid with $1.5 \mathrm{ml} \quad 0.8 \%$ Avicel RC-581 (FMC/DuPont; Wilmington, DE, USA) in medium and incubated for 3 days. Cells were fixed with $4 \%$ PFA at room temperature for $45 \mathrm{~min}$. After cells had been washed with PBS once, they were incubated in $0.5 \mathrm{ml}$ staining solution $(0.5 \%$ crystal violet and $0.1 \%$ triton in water) at room temperature. After $20 \mathrm{~min}$., the staining solution was rinsed off with water, virus-induced plaque formation quantified, and PFU/ml calculated.

\section{Multiplex ELISA}

$\mathrm{CM}$ was filtered and cytokine and chemokine protein levels in $\mathrm{CM}$ were measured using Luminex xMAP technology as in [3]. Multiplexing analysis was performed using a Luminex 100 system (Luminex, Austin, TX, USA) by Eve Technologies Corp. (Calgary, Alberta, Canada). Data are represented as $\mathrm{pg} / \mathrm{ml}$ for each SASP factor as a function of cellular density.

\section{Human lung studies}

Lungs from 9 patients who had died with SARS-CoV-2 (age $74 \pm 12$ years; mean \pm SD; 3 females, 6 males) were compared to 6 controls (age $78 \pm 19$ years; 2 females, 4 males) who did not have COPD, asthma, or other 
pulmonary diseases (Mayo Clinic Tissue Registry; Mayo Clinic IRB \#21-001392). Paraffin-embedded lung tissue was sectioned into $4 \mu \mathrm{m}$ sections, stained immunohistochemically for $\mathrm{p} 16^{\mathrm{INK} 4 a+}$ cells (Clone E6H4, \#705-4793, Roche Tissue Diagnostics, Indianapolis, IN, USA) using a VENTANA Discovery ULTRA instrument (Ventana Medical Systems; Oro Valley, AZ, USA), counterstained with hematoxylin, and scanned using a 40x objective Motic Slide Scanner (Motic Company; Xiamen, China). Images were virtually sliced into $300 \mathrm{x}$ $400 \mu \mathrm{m}$ numbered fields that were selected using a Microsoft Excel random number generator. Fifteen fields of p16 $6^{\mathrm{INK} 4 a+}$ lung cells were so counted/subject. Results were analyzed by an unpaired 2-tailed t-test.

\section{Statistical analysis}

All figures were plotted using Prism 9.0 (GraphPad). P value $\leq 0.05$ (two-sided) was considered statistically significant. Student's t-test was used to compare the equality of means from two independent samples, and Welch's correction was performed when two samples were determined to have significantly unequal variances (Levene's test). One-way ANOVA was used to compare means from three or more samples, and two-way ANOVA was used when there were two predictors. Tukey's Honestly Significant Difference (HSD) was used for post hoc pairwise comparisons where 4 means were being compared, while Fisher's Least Significant Difference (LSD) procedure was used when comparing 3 means. Paired t-tests and repeated measures ANOVA were used to account for nesting, i.e. correlated data across cells (preadipocytes) from the same subject. All $\mathrm{p}$ values $(<0.05)$ are indicated in the figures and Supplementary Table 1.

\section{AUTHOR CONTRIBUTIONS}

J.L.K. and T.T. generated the overall concept of the study. U.T., R.N., L.L., Y.Z., N.G., T.P., J.M.E.N., and A.X. performed experiments in this study. D.A.B., E.P., and S.L.D performed the statistical analyses. U.T, E.O.W.G., S.S., P.D.R, N.J.L., F.K., K.M.J.S., T.T., and J.L.K. designed the study and wrote the manuscript. All authors read, edited, and approved the final version of the manuscript.

\section{ACKNOWLEDGMENTS}

We are thankful to Christina Inman and Lennart Koepke for ordering the reagents used in the study.

\section{CONFLICTS OF INTEREST}

Patents on senolytic drugs and their uses are held by Mayo Clinic and the University of Minnesota. This research has been reviewed by the Mayo Clinic Conflict of Interest Review Board and was conducted in compliance with Mayo Clinic Conflicts of interest policies.

\section{FUNDING}

This work was supported by NIH grants R37AG013925 (J.L.K., T.T.), P01AG062413 (J.L.K., T.T., L.J.N., P.D.R.), P30AG050886 and U24AG056053 (D.B.A.), the Connor Fund (J.L.K., T.T.), Robert P. and Arlene R. Kogod (J.L.K.), Robert J. and Theresa W. Ryan (J.L.K., T.T.), the Noaber Foundation (J.L.K., T.T.), DFG (German Research Foundation) CRC 1279, SPP 1923, SP1600/6-1 (F.K., K.M.J.S.), BMBF (Federal Ministry of Education and Research) Restrict SARS-CoV-2 (F.K.), and BMBF Junior Research group (IMMUNOMOD; K.M.J.S.).

\section{REFERENCES}

1. Finelli L, Gupta V, Petigara T, Yu K, Bauer KA, Puzniak LA. Mortality Among US Patients Hospitalized With SARS-CoV-2 Infection in 2020. JAMA Netw Open. 2021; 4:e216556. https://doi.org/10.1001/jamanetworkopen.2021.6556 PMID: $\underline{3830226}$

2. Ganesh R, Grach SL, Bierle DM, Salonen BR, Collins NM, Joshi AY, Boeder N, Anstine CV, Mueller MR, Wight EC, Croghan IT, Badley AD, Carter RE, et al. The Female Predominant Persistent Immune Dysregulation of the Post COVID Syndrome: A Cohort Study. medRxiv. 2021. https://doi.org/10.1101/2021.05.25.21257820

3. Camell CD, Yousefzadeh MJ, Zhu Y, Prata LG, Huggins MA, Pierson M, Zhang L, O'Kelly RD, Pirtskhalava T, Xun $P$, Ejima K, Xue A, Tripathi $U$, et al. Senolytics reduce coronavirus-related mortality in old mice. Science. 2021; 373:eabe4832.

https://doi.org/10.1126/science.abe4832

PMID:34103349

4. Song S, Lam EW, Tchkonia T, Kirkland JL, Sun Y. Senescent Cells: Emerging Targets for Human Aging and Age-Related Diseases. Trends Biochem Sci. 2020; 45:578-92.

https://doi.org/10.1016/j.tibs.2020.03.008 PMID:32531228

5. Khosla S, Farr JN, Tchkonia T, Kirkland JL. The role of cellular senescence in ageing and endocrine disease. Nat Rev Endocrinol. 2020; 16:263-75. https://doi.org/10.1038/s41574-020-0335-y PMID:32161396

6. Campisi J, d'Adda di Fagagna F. Cellular senescence: when bad things happen to good cells. Nat Rev Mol Cell Biol. 2007; 8:729-40. 
https://doi.org/10.1038/nrm2233

PMID:17667954

7. Anderson R, Lagnado A, Maggiorani D, Walaszczyk A, Dookun E, Chapman J, Birch J, Salmonowicz H, Ogrodnik M, Jurk D, Proctor C, Correia-Melo C, Victorelli $S$, et al. Length-independent telomere damage drives post-mitotic cardiomyocyte senescence. EMBO J. 2019; 38:e100492.

https://doi.org/10.15252/embj.2018100492

PMID: $\underline{30737259}$

8. Conley SM, Hickson LJ, Kellogg TA, McKenzie T, Heimbach JK, Taner T, Tang H, Jordan KL, Saadiq IM, Woollard JR, Isik B, Afarideh M, Tchkonia T, et al. Human Obesity Induces Dysfunction and Early Senescence in Adipose Tissue-Derived Mesenchymal Stromal/Stem Cells. Front Cell Dev Biol. 2020; 8:197. https://doi.org/10.3389/fcell.2020.00197 PMID:32274385

9. Parikh P, Britt RD Jr, Manlove LJ, Wicher SA, Roesler A, Ravix J, Teske J, Thompson MA, Sieck GC, Kirkland JL, LeBrasseur N, Tschumperlin DJ, Pabelick CM, Prakash YS. Hyperoxia-induced Cellular Senescence in Fetal Airway Smooth Muscle Cells. Am J Respir Cell Mol Biol. 2019; 61:51-60.

https://doi.org/10.1165/rcmb.2018-01760C PMID:30508396

10. Lagnado A, Leslie J, Ruchaud-Sparagano $\mathrm{MH}$, Victorelli $S$, Hirsova $P$, Ogrodnik $M$, Collins AL, Vizioli MG, Habiballa L, Saretzki G, Evans SA, Salmonowicz H, Hruby $A$, et al. Neutrophils induce paracrine telomere dysfunction and senescence in ROS-dependent manner. EMBO J. 2021; 40:e106048.

https://doi.org/10.15252/embj.2020106048 PMID: $\underline{3764576}$

11. Pathak RU, Soujanya M, Mishra RK. Deterioration of nuclear morphology and architecture: A hallmark of senescence and aging. Ageing Res Rev. 2021; 67:101264.

https://doi.org/10.1016/i.arr.2021.101264 PMID:33540043

12. González-Gualda E, Baker AG, Fruk L, Muñoz-Espín D. A guide to assessing cellular senescence in vitro and in vivo. FEBS J. 2021; 288:56-80.

https://doi.org/10.1111/febs.15570 PMID: $\underline{32961620}$

13. Wang E. Senescent human fibroblasts resist programmed cell death, and failure to suppress $\mathrm{bcl} 2$ is involved. Cancer Res. 1995; 55:2284-92.

PMID: $\underline{7757977}$

14. Prata LG, Ovsyannikova IG, Tchkonia T, Kirkland JL. Senescent cell clearance by the immune system: Emerging therapeutic opportunities. Semin Immunol. 2018; 40:101275. https://doi.org/10.1016/j.smim.2019.04.003 PMID: $\underline{31088710}$

15. Kale A, Sharma A, Stolzing A, Desprez PY, Campisi J. Role of immune cells in the removal of deleterious senescent cells. Immun Ageing. 2020; 17:16. https://doi.org/10.1186/s12979-020-00187-9 PMID: $\underline{32518575}$

16. Kandhaya-Pillai R, Miro-Mur F, Alijotas-Reig J, Tchkonia T, Kirkland JL, Schwartz S. TNF $\alpha$-senescence initiates a STAT-dependent positive feedback loop, leading to a sustained interferon signature, DNA damage, and cytokine secretion. Aging (Albany NY). 2017; 9:2411-35. https://doi.org/10.18632/aging.101328 PMID:29176033

17. Zhu Y, Armstrong JL, Tchkonia T, Kirkland JL. Cellular senescence and the senescent secretory phenotype in age-related chronic diseases. Curr Opin Clin Nutr Metab Care. 2014; 17:324-28. https://doi.org/10.1097/MC0.0000000000000065 PMID:24848532

18. Tchkonia T, Zhu Y, van Deursen J, Campisi J, Kirkland JL. Cellular senescence and the senescent secretory phenotype: therapeutic opportunities. J Clin Invest. 2013; 123:966-72.

https://doi.org/10.1172/JCl64098

PMID:23454759

19. Coppé JP, Patil CK, Rodier F, Sun Y, Muñoz DP, Goldstein J, Nelson PS, Desprez PY, Campisi J. Senescence-associated secretory phenotypes reveal cell-nonautonomous functions of oncogenic RAS and the p53 tumor suppressor. PLoS Biol. 2008; 6:2853-68. https://doi.org/10.1371/journal.pbio.0060301 PMID:19053174

20. Xu M, Pirtskhalava T, Farr JN, Weigand BM, Palmer AK, Weivoda MM, Inman CL, Ogrodnik MB, Hachfeld CM, Fraser DG, Onken JL, Johnson KO, Verzosa GC, et al. Senolytics improve physical function and increase lifespan in old age. Nat Med. 2018; 24:1246-56. https://doi.org/10.1038/s41591-018-0092-9 PMID:29988130

21. Iske J, Seyda M, Heinbokel T, Maenosono R, Minami K, Nian Y, Quante M, Falk CS, Azuma H, Martin F, Passos JF, Niemann CU, Tchkonia T, et al. Senolytics prevent mt-DNA-induced inflammation and promote the survival of aged organs following transplantation. Nat Commun. 2020; 11:4289. https://doi.org/10.1038/s41467-020-18039-x PMID:32855397

22. Tchkonia T, Palmer AK, Kirkland JL. New Horizons: Novel Approaches to Enhance Healthspan Through Targeting Cellular Senescence and Related Aging 
Mechanisms. J Clin Endocrinol Metab. 2021; 106:e1481-87.

https://doi.org/10.1210/clinem/dgaa728

PMID:33155651

23. Wissler Gerdes EO, Zhu Y, Weigand BM, Tripathi U, Burns TC, Tchkonia T, Kirkland JL. Cellular senescence in aging and age-related diseases: Implications for neurodegenerative diseases. Int Rev Neurobiol. 2020; 155:203-34.

https://doi.org/10.1016/bs.irn.2020.03.019

PMID: $\underline{32854855}$

24. Wyld L, Bellantuono I, Tchkonia T, Morgan J, Turner O, Foss F, George J, Danson S, Kirkland JL. Senescence and Cancer: A Review of Clinical Implications of Senescence and Senotherapies. Cancers (Basel). 2020; 12:2134. https://doi.org/10.3390/cancers12082134 PMID:32752135

25. Pignolo RJ, Passos JF, Khosla S, Tchkonia T, Kirkland JL. Reducing Senescent Cell Burden in Aging and Disease. Trends Mol Med. 2020; 26:630-38. https://doi.org/10.1016/i.molmed.2020.03.005 PMID: $\underline{32589933}$

26. Kim SR, Jiang $K$, Ferguson CM, Tang $H$, Chen X, Zhu X, Hickson L, Tchkonia T, Kirkland JL, Lerman LO. Transplanted senescent renal scattered tubular-like cells induce injury in the mouse kidney. Am J Physiol Renal Physiol. 2020; 318:F1167-76. https://doi.org/10.1152/ajprenal.00535.2019 PMID:32223312

27. Palmer AK, Gustafson B, Kirkland JL, Smith U. Cellular senescence: at the nexus between ageing and diabetes. Diabetologia. 2019; 62:1835-41. https://doi.org/10.1007/s00125-019-4934-x PMID:31451866

28. Farr JN, Rowsey JL, Eckhardt BA, Thicke BS, Fraser DG, Tchkonia T, Kirkland JL, Monroe DG, Khosla S. Independent Roles of Estrogen Deficiency and Cellular Senescence in the Pathogenesis of Osteoporosis: Evidence in Young Adult Mice and Older Humans. J Bone Miner Res. 2019; 34:1407-18. https://doi.org/10.1002/jbmr.3729 PMID:30913313

29. Lewis-McDougall FC, Ruchaya PJ, Domenjo-Vila E, Shin Teoh T, Prata L, Cottle BJ, Clark JE, Punjabi PP, Awad W, Torella D, Tchkonia T, Kirkland JL, Ellison-Hughes GM. Aged-senescent cells contribute to impaired heart regeneration. Aging Cell. 2019; 18:e12931.

https://doi.org/10.1111/acel.12931

PMID:30854802

30. Ogrodnik M, Zhu Y, Langhi LGP, Tchkonia T, Krüger $P$, Fielder E, Victorelli S, Ruswhandi RA, Giorgadze N, Pirtskhalava T, Podgorni O, Enikolopov G, Johnson KO, et al. Obesity-Induced Cellular Senescence Drives
Anxiety and Impairs Neurogenesis. Cell Metab. 2019; 29:1061-77.e8.

https://doi.org/10.1016/j.cmet.2018.12.008

PMID:30612898

31. Tchkonia T, Kirkland JL. Aging, Cell Senescence, and Chronic Disease: Emerging Therapeutic Strategies. JAMA. 2018; 320:1319-20. https://doi.org/10.1001/jama.2018.12440 PMID:30242336

32. Ogrodnik $M$, Evans $S A$, Fielder E, Victorelli $S$, Kruger $P$, Salmonowicz $\mathrm{H}$, Weigand BM, Patel AD, Pirtskhalava T, Inman CL, Johnson KO, Dickinson SL, Rocha A, et al. Whole-body senescent cell clearance alleviates agerelated brain inflammation and cognitive impairment in mice. Aging Cell. 2021; 20:e13296. https://doi.org/10.1111/acel.13296 PMID:33470505

33. Bian X, Griffin TP, Zhu X, Islam MN, Conley SM, Eirin A, Tang $H$, O'Shea PM, Palmer AK, McCoy RG, Herrmann SM, Mehta RA, Woollard JR, et al. Senescence marker activin $A$ is increased in human diabetic kidney disease: association with kidney function and potential implications for therapy. BMJ Open Diabetes Res Care. 2019; 7:e000720.

https://doi.org/10.1136/bmjdrc-2019-000720

PMID:31908790

34. Schafer MJ, White TA, lijima K, Haak AJ, Ligresti G, Atkinson EJ, Oberg AL, Birch J, Salmonowicz H, Zhu Y, Mazula DL, Brooks RW, Fuhrmann-Stroissnigg $\mathrm{H}$, et al. Cellular senescence mediates fibrotic pulmonary disease. Nat Commun. 2017; 8:14532.

https://doi.org/10.1038/ncomms14532 PMID:28230051

35. Xu M, Bradley EW, Weivoda MM, Hwang SM, Pirtskhalava T, Decklever T, Curran GL, Ogrodnik M, Jurk D, Johnson KO, Lowe V, Tchkonia T, Westendorf JJ, Kirkland JL. Transplanted Senescent Cells Induce an Osteoarthritis-Like Condition in Mice. J Gerontol A Biol Sci Med Sci. 2017; 72:780-85.

https://doi.org/10.1093/gerona/glw154 PMID:27516624

36. Laing AG, Lorenc A, Del Molino Del Barrio I, Das A, Fish M, Monin L, Muñoz-Ruiz M, McKenzie DR, Hayday TS, Francos-Quijorna I, Kamdar S, Joseph M, Davies D, et al. Author Correction: A dynamic COVID-19 immune signature includes associations with poor prognosis. Nat Med. 2020; 26:1951. https://doi.org/10.1038/s41591-020-01186-5 PMID:33247289

37. Lester SN, Li K. Toll-like receptors in antiviral innate immunity. J Mol Biol. 2014; 426:1246-64. https://doi.org/10.1016/i.jmb.2013.11.024 PMID:24316048 
38. Khanmohammadi S, Rezaei N. Role of Toll-like receptors in the pathogenesis of COVID-19. J Med Virol. 2021; 93:2735-39.

https://doi.org/10.1002/imv.26826 PMID:33506952

39. Condor Capcha JM, Lambert G, Dykxhoorn DM, Salerno AG, Hare JM, Whitt MA, Pahwa S, Jayaweera DT, Shehadeh LA. Generation of SARS-CoV-2 Spike Pseudotyped Virus for Viral Entry and Neutralization Assays: A 1-Week Protocol. Front Cardiovasc Med. 2021; 7:618651.

https://doi.org/10.3389/fcvm.2020.618651

PMID: $\underline{3521067}$

40. Hall BM, Balan V, Gleiberman AS, Strom E, Krasnov $P$, Virtuoso LP, Rydkina E, Vujcic S, Balan K, Gitlin II, Leonova KI, Consiglio CR, Gollnick SO, et al. p16(Ink4a) and senescence-associated $\beta$-galactosidase can be induced in macrophages as part of a reversible response to physiological stimuli. Aging (Albany NY). 2017; 9:1867-84.

https://doi.org/10.18632/aging.101268

PMID:28768895

41. Palmer AK, Tchkonia T, Kirkland JL. Senolytics: Potential for Alleviating Diabetes and Its Complications. Endocrinology. 2021; 162:bqab058. https://doi.org/10.1210/endocr/bqab058 PMID:33705532

42. Robbins PD, Jurk D, Khosla S, Kirkland JL, LeBrasseur NK, Miller JD, Passos JF, Pignolo RJ, Tchkonia T, Niedernhofer LJ. Senolytic Drugs: Reducing Senescent Cell Viability to Extend Health Span. Annu Rev Pharmacol Toxicol. 2021; 61:779-803.

https://doi.org/10.1146/annurev-pharmtox-050120105018 PMID:32997601

43. Cavalcante-Silva LH, Carvalho DC, Lima ÉA, Galvão JG, da Silva JS, Sales-Neto JM, Rodrigues-Mascarenhas S. Neutrophils and COVID-19: The road so far. Int Immunopharmacol. 2021; 90:107233.

https://doi.org/10.1016/i.intimp.2020.107233 PMID:33290963

44. Greco GI, Noale M, Trevisan C, Zatti G, Dalla Pozza M, Lazzarin M, Haxhiaj L, Ramon R, Imoscopi A, Bellon S, Maggi S, Sergi G. Increase in Frailty in Nursing Home Survivors of Coronavirus Disease 2019: Comparison With Noninfected Residents. J Am Med Dir Assoc. 2021; 22:943-47.e3.

https://doi.org/10.1016/j.jamda.2021.02.019

PMID:33757725

45. Wissler Gerdes EO, Zhu Y, Tchkonia T, Kirkland JL. Discovery, development, and future application of senolytics: theories and predictions. FEBS J. 2020; 287:2418-27.

https://doi.org/10.1111/febs.15264

PMID:32112672
46. Zhu Y, Tchkonia T, Pirtskhalava $T$, Gower AC, Ding $H$, Giorgadze N, Palmer AK, Ikeno Y, Hubbard GB, Lenburg M, O'Hara SP, LaRusso NF, Miller JD, et al. The Achilles' heel of senescent cells: from transcriptome to senolytic drugs. Aging Cell. 2015; 14:644-58.

https://doi.org/10.1111/acel.12344 PMID:25754370

47. Zhu $Y$, Tchkonia T, Fuhrmann-Stroissnigg $H$, Dai HM, Ling YY, Stout MB, Pirtskhalava T, Giorgadze N, Johnson KO, Giles CB, Wren JD, Niedernhofer L, Robbins PD, Kirkland JL. Identification of a novel senolytic agent, navitoclax, targeting the Bcl-2 family of anti-apoptotic factors. Aging Cell. 2016; 15:428-35.

https://doi.org/10.1111/acel.12445 PMID:26711051

48. Zhu Y, Doornebal EJ, Pirtskhalava T, Giorgadze N, Wentworth M, Fuhrmann-Stroissnigg $H$, Niedernhofer LJ, Robbins PD, Tchkonia T, Kirkland JL. New agents that target senescent cells: the flavone, fisetin, and the $B C L-X_{L}$ inhibitors, A1331852 and A1155463. Aging (Albany NY). 2017; 9:955-63.

https://doi.org/10.18632/aging.101202 PMID:28273655

49. Fuhrmann-Stroissnigg $H$, Ling $Y Y$, Zhao J, McGowan SJ, Zhu Y, Brooks RW, Grassi D, Gregg SQ, Stripay JL, Dorronsoro A, Corbo L, Tang P, Bukata C, et al. Identification of HSP90 inhibitors as a novel class of senolytics. Nat Commun. 2017; 8:422.

https://doi.org/10.1038/s41467-017-00314-z PMID:28871086

50. Yousefzadeh MJ, Zhu Y, McGowan SJ, Angelini L, Fuhrmann-Stroissnigg $\mathrm{H}, \mathrm{Xu} \mathrm{M}$, Ling $\mathrm{YY}$, Melos $\mathrm{KI}$, Pirtskhalava T, Inman CL, McGuckian C, Wade EA, Kato $\mathrm{JI}$, et al. Fisetin is a senotherapeutic that extends health and lifespan. EBioMedicine. 2018; 36:18-28.

https://doi.org/10.1016/i.ebiom.2018.09.015 PMID:30279143

51. Mukherjee R, Bhattacharya A, Bojkova D, Mehdipour $A R$, Shin D, Khan KS, Hei-Yin Cheung $H$, Wong KB, Ng WL, Cinatl J, Geurink PP, van der Heden van Noort GJ, Rajalingam $\mathrm{K}$, et al. Famotidine inhibits toll-like receptor 3-mediated inflammatory signaling in SARSCoV-2 infection. J Biol Chem. 2021; 297:100925.

https://doi.org/10.1016/i.jbc.2021.100925 PMID: $\underline{34214498}$

52. Anwar MA, Shah M, Kim J, Choi S. Recent clinical trends in Toll-like receptor targeting therapeutics. Med Res Rev. 2019; 39:1053-90.

https://doi.org/10.1002/med.21553 PMID:30450666

53. Tchkonia T, Tchoukalova YD, Giorgadze N, Pirtskhalava T, Karagiannides I, Forse RA, Koo A, Stevenson M, Chinnappan D, Cartwright A, Jensen MD, Kirkland JL. Abundance of two human preadipocyte subtypes with distinct capacities for replication, adipogenesis, and 
apoptosis varies among fat depots. Am J Physiol Endocrinol Metab. 2005; 288:E267-77.

https://doi.org/10.1152/ajpendo.00265.2004

PMID:15383371

54. Palmer AK, Xu M, Zhu Y, Pirtskhalava T, Weivoda MM, Hachfeld CM, Prata LG, van Dijk TH, Verkade E, Casaclang-Verzosa G, Johnson KO, Cubro H, Doornebal EJ, et al. Targeting senescent cells alleviates obesityinduced metabolic dysfunction. Aging Cell. 2019; 18:e12950.

https://doi.org/10.1111/acel.12950

PMID:30907060

55. Xu M, Palmer AK, Ding H, Weivoda MM, Pirtskhalava T, White TA, Sepe A, Johnson KO, Stout MB, Giorgadze N, Jensen MD, LeBrasseur NK, Tchkonia T, Kirkland JL. Targeting senescent cells enhances adipogenesis and metabolic function in old age. Elife. 2015; 4:e12997.
https://doi.org/10.7554/eLife.12997

PMID:26687007

56. Hayn $M$, Hirschenberger $M$, Koepke $L$, Nchioua $R$, Straub JH, Klute S, Hunszinger V, Zech F, Prelli Bozzo C, Aftab W, Christensen MH, Conzelmann C, Müller JA, et al. Systematic functional analysis of SARS-CoV-2 proteins uncovers viral innate immune antagonists and remaining vulnerabilities. Cell Rep. 2021; 35:109126.

https://doi.org/10.1016/i.celrep.2021.109126

PMID:33974846

57. Conzelmann C, Gilg A, Groß R, Schütz D, Preising N, Ständker L, Jahrsdörfer B, Schrezenmeier $H$, Sparrer KM, Stamminger T, Stenger S, Münch J, Müller JA. An enzyme-based immunodetection assay to quantify SARS-CoV-2 infection. Antiviral Res. 2020; 181:104882. https://doi.org/10.1016/j.antiviral.2020.104882 PMID:32738255 


\section{SUPPLEMENTARY MATERIALS}

\section{Supplementary Figures}

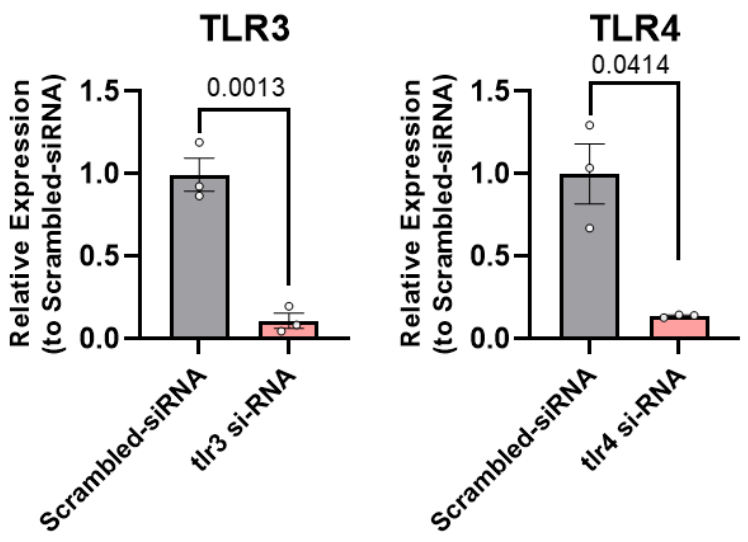

Supplementary Figure 1. siRNA mediated knockdown of TLR-3 and TLR-4 in senescent preadipocytes. Knockdown by siRNA was confirmed by rtPCR after 2 days in senescent preadipocytes $(n=3)$. Data are expressed as a function of scrambled siRNA-treated senescent cells; mean +/- SEM, paired 2-tailed Student's t-tests.

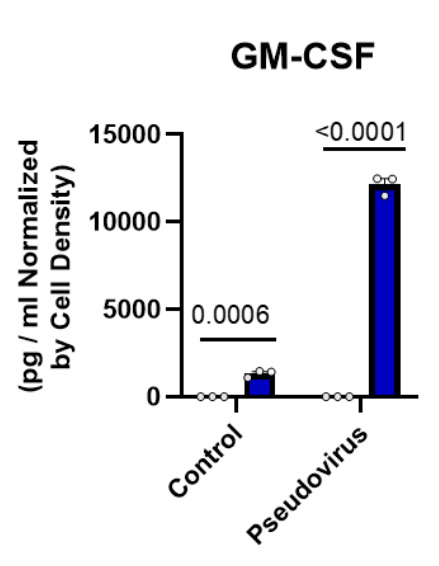

CXCL9

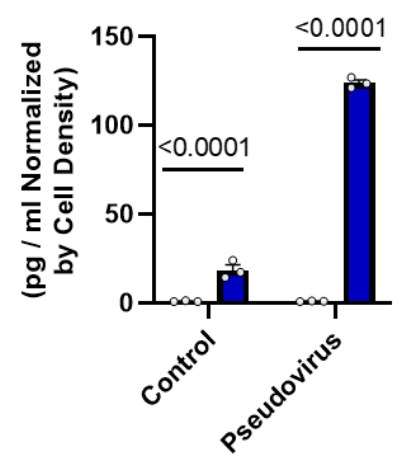

IL-6

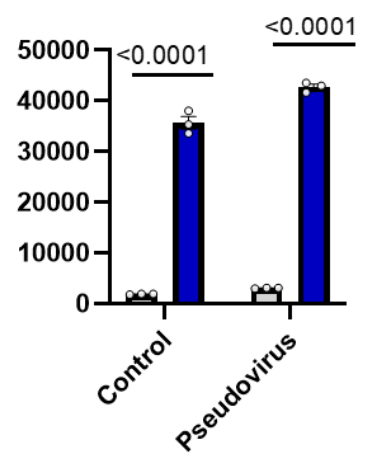

CXCL5

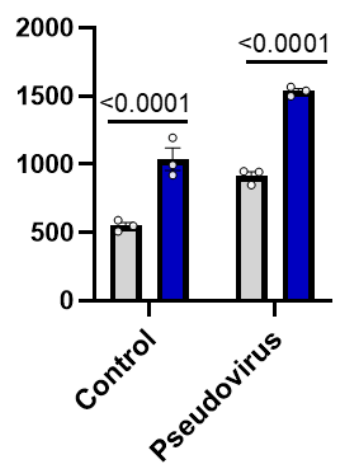

IP-10
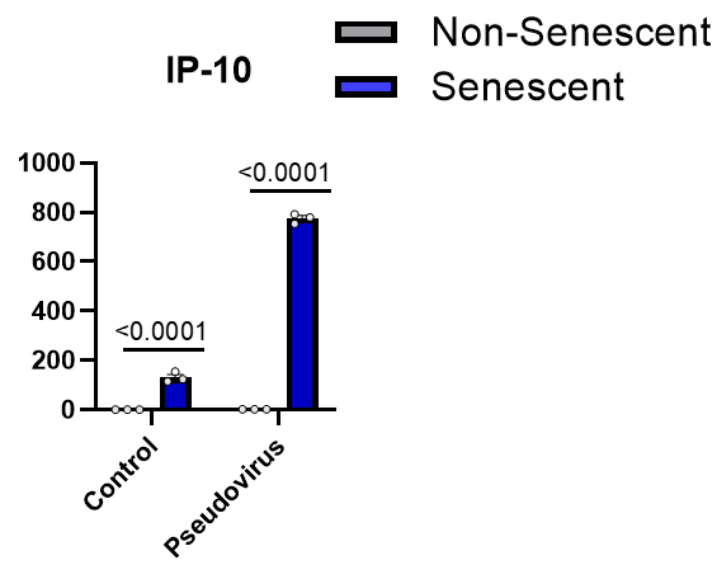

\section{CXCL1}

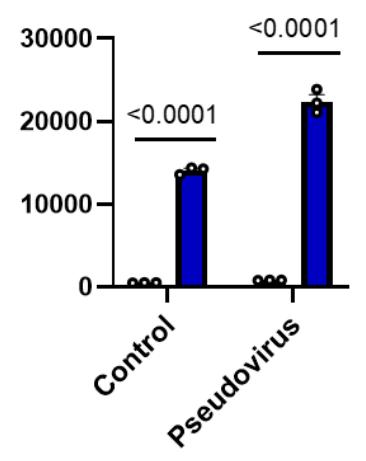

Supplementary Figure 2. Pseudovirus amplifies the SASP in senescent kidney endothelial cells. SASP factors were assayed in senescent and non-senescent kidney endothelial cells treated with pseudovirus for $96 \mathrm{hrs}$. Data are shown as a function of cell number; mean +/- SEM, 2-way ANOVA and post hoc comparison Fisher's LSD. 


\section{Supplementary Tables}

Supplementary Table 1. Significant p values in addition to those shown in Figures 3, 4.

\begin{tabular}{|c|c|c|}
\hline Figures & Comparisons & p values \\
\hline \multirow{2}{*}{$3 \mathrm{~B}$} & IL-1 $\beta$, TLR-3 antagonist vs. TLR-3 siRNA & 0.0114 \\
\hline & IP-10, TLR-3 antagonist vs. TLR-3 siRNA & 0.0175 \\
\hline \multirow[t]{3}{*}{$3 \mathrm{C}$} & Il- $1 \alpha$ senescent, 24 vs. 96 hrs. & 0.0466 \\
\hline & Il- $1 \alpha$, TLR-4 siRNA $v s$. control & 0.0132 \\
\hline & IL-6, TLR-3 siRNA vs. control & 0.0450 \\
\hline \multirow[t]{3}{*}{$4 \mathrm{~B}$} & IL-6, TLR-4 siRNA vs. control & 0.0193 \\
\hline & IL-8, TLR-4 siRNA vs. control & 0.0065 \\
\hline & IP-10, TLR-4 siRNA vs. control & 0.0288 \\
\hline
\end{tabular}

Supplementary Table 2. Information about the control lung biopsy patients in Figure 5.

\begin{tabular}{lcc}
\hline Gender & Cause of death & Age \\
\hline F & Car accident & 92 \\
F & Car accident & 100 \\
M & Myocardial infarction (from atherosclerotic cardiovascular disease) & 52 \\
M & Drowning. Lungs without significant diagnostic abnormalities. No rigor mortis (death less than 24 hrs.) & 72 \\
M & Cerebrovascular accident & 92 \\
M & Dementia/malnutrition & 59 \\
\hline
\end{tabular}

Supplementary Table 3. Information about the COVID lung biopsy patients in Figure 5.

\begin{tabular}{|c|c|c|}
\hline Gender & Cause of death/specified COVID complication & Age \\
\hline M & Respiratory failure due to COVID & 71 \\
\hline M & Developed severe hypoxemia. Bronchoscopy did not reveal clear reversible cause & 73 \\
\hline M & $\begin{array}{c}\text { SARS-CoV-2 bronchopneumonia, lethargic, generalized muscle weakness, hypotension, and continued } \\
\text { hallucinations }\end{array}$ & 93 \\
\hline $\mathrm{F}$ & $\begin{array}{l}\text { Aspiration pneumonia in the setting of a recent SARS-CoV-2 infection. The deceased began antibiotic } \\
\text { therapy, however patient experienced significant decline in mentation and renal function }\end{array}$ & 89 \\
\hline M & $\begin{array}{c}\text { Acute respiratory distress syndrome (ARDS). Family elected to have compassionate ventilator } \\
\text { withdrawal }\end{array}$ & 72 \\
\hline $\mathrm{F}$ & $\begin{array}{c}\text { COVID-19 associated pneumonia in the setting of multiple chronic medical conditions and missed } \\
\text { hemodialysis }\end{array}$ & 71 \\
\hline $\mathrm{F}$ & $\begin{array}{l}\text { COVID-19 infection requiring intubation, multiple strokes with residual left hemiparesis, diabetes } \\
\text { mellitus type } 2 \text {, coronary artery disease, essential hypertension, acute respiratory failure, and cognitive } \\
\text { decline }\end{array}$ & 70 \\
\hline M & $\begin{array}{l}\text { CT chest showed findings consistent with COVID infection with profound hypoxemia. Palliative care } \\
\text { was consulted and patient transitioned to DNR }\end{array}$ & 76 \\
\hline M & Multiple GI bleeds. Pneumothorax infections. Massive transfusion and death & 51 \\
\hline
\end{tabular}

